\title{
Active filtering capability based on the RSC control of WECS equipped with a DFIG
}

\author{
Touati Abdelwahed ${ }^{1}$, Majdoul Radouane ${ }^{2}$, Aboulfatah Mohamed ${ }^{3}$, Rabbah Nabila ${ }^{4}$ \\ ${ }_{1,2,}^{4}$ Laboratory of Structural Engineering, Intelligent Systems \& Electrical Energy ENSAM, \\ Hassan II University, Morocco \\ ${ }^{3}$ Laboratory analysis of signal and information processing from the Faculty of Science and Technology, \\ Hassan 1er University of Settat, Morocco
}

\begin{tabular}{l}
\hline \hline Article Info \\
\hline Article history: \\
Received Apr 15, 2021 \\
Revised Jun 14, 2021 \\
Accepted Jun 20, 2021
\end{tabular}

Keywords:

DFIG

FTSMC

GSC

MPPT

RSC

SAPF

Theory of instantaneous active and reactive powers $\mathrm{PQ}$

\begin{abstract}
The increasing integration of decentralized production from renewable energies on the electricity grids should contribute to improving the stability and quality of the energy produced. The main objective of this work is to prove how renewable energy sources can improve the quality of electrical energy in the grid. In particular, controlled by the oriented flux technique, a double-feed induction generator DFIG driven by a wind turbine is together used to produce active power to the electrical network and to compensate the current harmonics generated by a non-linear load, which leads to improve the supplied energy quality. The Active filtering function consists first of all in identifying the current harmonics using the theory of instantaneous active and reactive powers quality (PQ). Then, the closed loop based on the fast terminal sliding mode control (FTSMC) control allows both the generator to follow the optimal operating point of the wind turbine and to compensate for the current harmonics. The Analysis and simulation results using MATLAB/Simulink confirm the effectiveness and the limits of the proposed methods and also show the performances of the law control which provides flexibility, high precision and fast response.
\end{abstract}

This is an open access article under the CC BY-SA license.

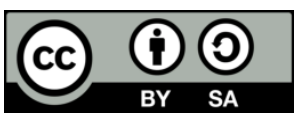

\section{Corresponding Author:}

Touati Abdelwahed

Department of Electrical Engineering

Laboratory of Structural Engineering, Intelligent Systems \& Electrical Energy ENSAM-Casablanca

Hassan II University, Morocco

Email: touati_2010@hotmail.com

\begin{tabular}{llll} 
NOMENCLATUR & & & \\
\hline DFIG & Doubly Fed Induction & $w_{r}$ & Pulsation of rotor currents (rd/s) \\
RSC & Rotor side converter & $p$ & Number of pole pairs of the DFIG \\
GSC & Grid side converter & $\Omega_{r}$ & Mechanical angular speed (rd/s) \\
WECS & Wind Energy Conversion & $v_{S d}, v_{S q}$ & Direct and quadratic stator \\
MPPT & Maximum Power Point & $v_{r d}, v_{r q}$ & Direct and quadratic rotor \\
$i_{r d}^{* *}, i_{r q}^{* *}$ & $\overline{\mathrm{d}}$-q rotor currents & $P_{S}, Q_{S}$ & Active and reactive stator powers \\
$\emptyset_{S d}, \emptyset_{S q}$ & d-q stator flux & $T_{E M}$ & The electromagnetic torque (N.m) \\
$\emptyset_{r d}, \emptyset_{r q}$ & d-q rotor flux components. & $V_{S}$ & The RMS value of the network \\
$i_{S d}, i_{S q}$ & d-q stator currents. & $v_{S 1}, v_{S 2}, v_{S 3}$ & Three phase voltages. \\
\hline
\end{tabular}




\begin{tabular}{|c|c|c|c|}
\hline$i_{r d}, i_{r q}$ & d-q rotor currents. & $S_{d}, S_{q}$ & d-q components of sliding \\
\hline$L_{S}, L_{r}$ & Stator and rotor & $P_{r}, Q_{r}$ & Active and reactive rotor powers \\
\hline$L_{M}$ & Magnetizing inductance & $v_{S \alpha}, v_{S \beta}$ & Components of the stator voltage \\
\hline$\sigma$ & Blondel dispersion & & \\
\hline$R_{S}, R_{r}$ & Stator and rotor resistances & $i_{S \alpha}, i_{S \beta}$ & Components of the stator current \\
\hline Vdc & DC link voltage & & in the $\alpha \beta$ reference. \\
\hline$w_{S}$ & Pulsation of synchronism & $i_{C h 1}, i_{C h 2}, i_{C h 3}$ & Currents of the non-linear load. \\
\hline THD $\%$ & Harmonic distortion rate & $\overline{\mathrm{p}}, \tilde{p}$ & $\begin{array}{l}\text { Continuous and alternative } \\
\text { components of Active power. }\end{array}$ \\
\hline SAPF & Shunt Active Power Filter & $\overline{\mathrm{q}}, \tilde{q}$ & $\begin{array}{l}\text { Continuous and alternative } \\
\text { components of reactive power. }\end{array}$ \\
\hline
\end{tabular}

\section{INTRODUCTION}

The development of power electronics, the increase in powers involved and the progressive flexibility of the semiconductors use have encouraged the association of statics powers converters with electrical machines. These devices based on electronic components absorb a non-sinusoidal current and therefore behave as harmonic generators consuming reactive power; these are the main cause of electrical network disturbances and harmonic production [1]. When using linear loads on an electrical network, the current and the voltage is at the same frequency imposed by the grid. The presence of non-linear loads includes common office equipment such as computers and scanners, fluorescent lighting, battery chargers and variable-speed drives, contribute to generate a harmonic current. This will cause additional losses and reduce the performance of the equipments [2]. Therefore, power quality problems have become an important concern nowadays. Standards for mitigating harmonic current effects have been recommended to limit problems not only result in degradation of the power factor, but also lead to failures of sensitive devices and equipment overheating [3].

Wind is the second widely used renewable energy source after hydropower [4]. More the wind is one of the lowest-priced energy sources available today. These decentralized sources can not only behave as active generators in the distribution networks, but must produce system services (reactive power compensation) like conventional generators and participate in improving the quality of electrical energy (active filtering function) [5], [6]. In the first time, passive filters had been introduced to eliminate the current harmonic effects. However, these types of filters are highly sensitive to random variations in power system parameters and can cause resonances parallel according to the source impedance [7]. Active power filters have been developed to overcome the disadvantages of passive filters and to provide a more reliable and flexible compensation. This allows for a more stable network. Hoon et al. [8], an isolated shunt active power filter is tested to reduce the harmonic currents produced by a non-linear load. The simulation results of the grid currents after filtering shows a THD\% harmonic distortion rate (12.08\%) which can be more improved.

Generally [9], shunt active filters are intended to act in a direct and dynamic manner to compensate harmonics or mitigate their effects on power systems. To achieve this goal, the method of identifying harmonic reference values should respond in real time and accurately to ensure good filtering quality. The algorithms for identifying harmonic references of currents or voltages are grouped in the literature in two domains, the frequency domain or the time domain. The methods of identifying harmonics in the time domain are characterized by a fast response time and a minimal computation compared to the methods in the frequency domain [10]. The instantaneous powers method PQ introduced by Akagi et al. [11], uses the Concordia's transformation of simple voltages and currents absorbed by the non-linear load, in order to calculate instantaneous real and imaginary powers. The fundamental component of the powers is transformed into a continuous component and the harmonic components into oscillatory components. This transformation is necessary to keep only the term representing the harmonic components.

Ahmed and Ali [12], the grid side converter (GSC) of wind energy conversion sys (WECS) equipped with DFIG was used as a shunt active power filter (SAPF) for improving the power quality. With a control strategy using PI controller, the quality of the currents injected into the network can be more improved [13]. In previous work [14], we proposed a control algorithm to extract the optimum power point in the WECS, that allowed the doubly fed induction generator DFIG to track the optimal operation points of the wind turbine system under fluctuating wind conditions, and the tracking process speeds up over time. Indeed, we had proposed an advanced maximum power point tracking (MPPT) technique. The control strategy consisted in inserting a Kalman observer to estimate the mechanical torque, then to synthesize an MPPT controller by back-stepping approach to generate the electromagnetic torque reference like in Figure 1. So, a 
high order sliding mode controller was synthesized in order to regulate both the electromagnetic torque and the stator reactive power to achieve the control aims.

In this work, by using the same control of the rotor side converter rotor side converter (RSC) like in Figure 2. We aim both to improve the power efficiency and to reduce the current harmonics generated by non-linear loads. We investigate the non-linear control technique based to the new robust fast terminal sliding mode control (FTSMC). The dynamic terminal sliding mode controller is formulated based on Lyapunov theory such that the sliding phase of the closed-loop control system can be guaranteed, also chattering phenomenon caused by the classical sliding mode control can be eliminated, and high precision performance is achieved [15].

The document is organized: in section (2.1), the operational control objectives are presented. Then in paragraph (2.2) the mathematical model of the DFIG is detailed. In section (2.3), the generation of harmonic current references is developed, using the principle of the instantaneous power PQ method widely used in the literature. In (2.4), the control law using fast terminal sliding mode control FTSMC is synthesized. The performance of the controller is illustrated by simulations in section 3 and compared to the simulation résults of the technique based on the second order sliding mode control developed in [10]. Finaly, we conclude and a list of references complete the paper.

\section{STRATEGY OF CONTROL}

\subsection{Control objective}

There are two operational objectives of the control strategy:

- Identify harmonic currents using the instantaneous power PQ method widely used in the literature. Then define the equivalent rotor currents.

- Design a law using Fast terminal sliding mode control FTSMC to ensure a better harmonic distortion rate of the network's currents and a unit power factor.

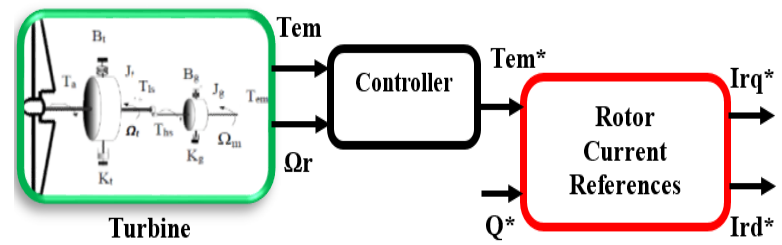

Figure 1. Principle of the MPPT bloc references generator

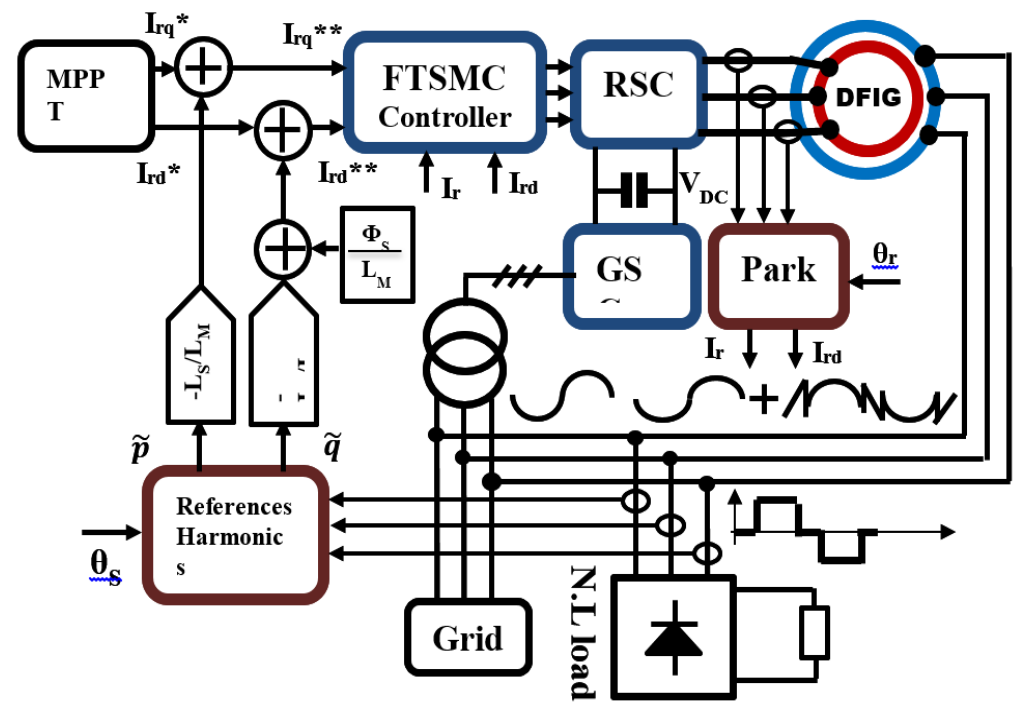

Figure 2. Principle of the control strategy 


\subsection{Modeling of the DFIG}

The vector control of the doubly fed induction generator DFIG provides faster response dynamics and better torque control accuracy. In this context, a vector control strategy with oriented stator flux has been developed. The electrical equations from the generator in the park frame are written [16]:

The stator and rotor flux are expressed by:

$$
\left\{\begin{array}{l}
\emptyset_{S d}=L_{S} \cdot i_{S d}+L_{M} \cdot i_{r d} \\
\emptyset_{S q}=L_{S} \cdot i_{S q}+L_{M} \cdot i_{r q} \\
\emptyset_{r d}=L_{r} \cdot i_{r d}+L_{M} \cdot i_{S d} \\
\emptyset_{r q}=L_{r} \cdot i_{r q}+L_{M} \cdot i_{S q}
\end{array}\right.
$$

The relation (2) gives the stator and rotor voltages equations, [17]:

$$
\left\{\begin{array}{l}
v_{S d}=R_{S} \cdot i_{S d}+\frac{d \emptyset_{S d}}{d t}-\omega_{S} \cdot \emptyset_{S q} \\
v_{S q}=R_{S} \cdot i_{S q}+\frac{d \emptyset_{S q}}{d t}+\omega_{S} \cdot \emptyset_{S d} \\
v_{r d}=R_{r} \cdot i_{r d}+\frac{d \emptyset_{r d}}{d t}-\omega_{r} \cdot \emptyset_{r q} \\
v_{r q}=R_{r} \cdot i_{r q}+\frac{d \emptyset_{r q}}{d t}+\omega_{r} \cdot \emptyset_{r d}
\end{array}\right.
$$

The relation (3) define the stator active, reactive powers and the electromagnetic torque [18]:

$$
\left\{\begin{array}{c}
P_{S}=v_{S d} \cdot i_{S d}+v_{S q} \cdot i_{S q} \\
Q_{S}=v_{S q} \cdot i_{S d}-v_{S d} \cdot i_{S q} \\
T_{E M}=p \cdot L_{M} \cdot\left(i_{r d} i_{S q}-i_{r q} i_{S d}\right)
\end{array}\right.
$$

by setting the quadratic component of the stator's flux to null value and neglecting the value of the stator winding resistor RS, the voltage and flux equations of the stator winding are simplified in steady state as:

$$
\left\{\begin{array}{c}
\emptyset_{S d}=\emptyset_{S}=c t e \Rightarrow \frac{d \emptyset_{S d}}{d t}=0 \\
R_{S} \simeq 0 \Rightarrow v_{S d}=0
\end{array}\right.
$$

Therefore, combining (1) and (4) we get the following simplified expressions:

$$
\left\{\begin{array}{c}
i_{S q}=\frac{-L_{M}}{L_{S}} \cdot i_{r q} \\
i_{S d}=\left(\frac{\emptyset_{S}}{L_{S}}-\frac{L_{M} \cdot i_{r d}}{L_{S}}\right)
\end{array}\right.
$$

Using the Blondel dispersion coefficient $\sigma,(1)$ and (2) we obtain the simplified expressions:

$$
\left\{\begin{array}{c}
\frac{d i_{r d}}{d t}=\frac{1}{L_{r} \sigma}\left(v_{r d}-R_{r} i_{r d}+w_{r} L_{r} \sigma i_{r q}\right) \\
\frac{d i_{r q}}{d t}=\frac{1}{L_{r} \sigma}\left(v_{r q}-R_{r} i_{r q}-w_{r} L_{r} \sigma i_{r d}-w_{r} \cdot \frac{L_{M}}{L_{S}} \phi_{S}\right)
\end{array}\right.
$$

Moreover, relation (3) can be written as:

$$
\left\{\begin{array}{c}
P_{S}=-\sqrt{3} \cdot V_{S} \cdot \frac{L_{M}}{L_{S}} \cdot i_{r q} \\
Q_{S}=\sqrt{3} \cdot V_{S} \cdot\left(\emptyset_{S}-L_{M} \cdot i_{r d}\right) \cdot \frac{1}{L_{S}} \\
T_{E M}=-p \cdot \frac{L_{M}}{L_{S}} \cdot \emptyset_{S} \cdot i_{r q}
\end{array}\right.
$$

\subsection{References harmonic generator}

Figure 3 shows the shape of the three-phase currents absorbed by the non-linear load formed by a rectifier circuit. The principle of the instantaneous power method adopted here consists of the transition from three-phase systems consisting of simple voltages and line currents to a system $\alpha \beta$ using the Concordia transformation. The Concordia transition matrix is [19]: 


$$
\begin{aligned}
& {\left[C_{32}\right]=\sqrt{\frac{2}{3}} \cdot\left[\begin{array}{ccc}
1 & \frac{-1}{2} & \frac{-1}{2} \\
0 & \frac{\sqrt{3}}{2} & \frac{-\sqrt{3}}{2}
\end{array}\right]} \\
& {\left[\begin{array}{l}
v_{S \alpha} \\
v_{S \beta}
\end{array}\right]=\left[C_{32}\right] \cdot\left[\begin{array}{l}
v_{S 1} \\
v_{S 2} \\
v_{S 3}
\end{array}\right]} \\
& {\left[\begin{array}{l}
i_{c h \alpha} \\
v_{c h \beta}
\end{array}\right]=\left[C_{32}\right] \cdot\left[\begin{array}{l}
i_{c h 1} \\
i_{c h 2} \\
i_{c h 3}
\end{array}\right]}
\end{aligned}
$$

The relation (11) gives the instantaneous active and reactive powers expressions.

$$
\left[\begin{array}{l}
p \\
q
\end{array}\right]=\left[\begin{array}{cc}
v_{S \alpha} & v_{S \beta} \\
-v_{S \beta} & v_{S \alpha}
\end{array}\right] \cdot\left[\begin{array}{l}
i_{S \alpha} \\
i_{S \beta}
\end{array}\right]
$$

Each of the instantaneous powers consists of two components: direct and alternative.

$$
\left\{\begin{array}{l}
p=\bar{p}+\tilde{p} \\
q=\bar{q}+\tilde{q}
\end{array}\right.
$$

Where $\tilde{p}$ and $\tilde{q}$ represent the alternative components related to the interaction between the simple voltages and the harmonic currents of the different orders. To extract the harmonic components from the instantaneous active and reactive powers, we use a second order low-pass filter, as shown in Figure 3. From (7), we define the rotor current references corresponding to the harmonic currents produced by the non-linear load.

$$
i_{r q c h}=\tilde{p} \cdot \frac{-L_{S}}{U_{S} \cdot L_{M}} \text { and } i_{r d c h}=\left(\frac{\emptyset_{S}}{L_{M}}-\frac{\tilde{q} \cdot L_{S}}{U_{S} \cdot L_{M}}\right)
$$

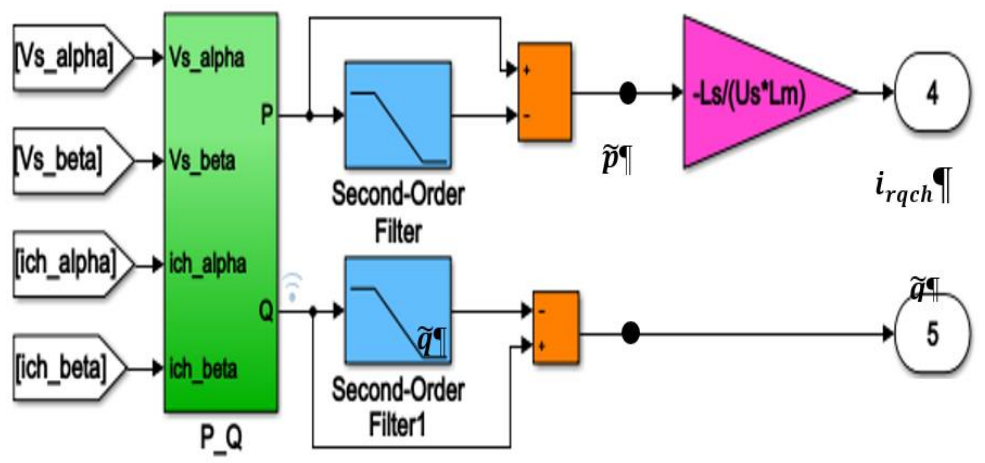

Figure 3. Scheme for extraction of harmonic currents under MATLAB/SIMULINK

\subsection{Dynamic fast terminal SMC controller synthesis}

\subsubsection{Principle of FTSMC controller}

The classical commands by sliding mode ensure an asymptotic error convergence; while the fast terminal sliding mode control (FTSMC) techniques ensure finite time convergence of the error [20].

Let us consider the generalized following sliding function:

$$
s=\dot{x}(t)+\alpha x(t)+\beta|x(t)|^{q} / p \cdot \operatorname{sgn}(x(t))
$$

Where $\alpha, \beta>0 \& q, p(q<p)$ are positive parameters.

When s tends to $0, \mathrm{x}(\mathrm{t})$ tends to 0 in finite time. The relation (14) become:

$$
\dot{x}(t)=-\alpha x(t)-\beta x(t)^{q / p}
$$


From relation (15), we write:

$$
x^{-q / p} \cdot \frac{d x}{d t}+\alpha \cdot x^{(1-q / p)}=-\beta
$$

We choose the variable y as:

$$
y=x^{\frac{(p-q)}{p}} \rightarrow \frac{d y}{d t}=\frac{(p-q)}{p} \cdot x^{\frac{-q}{p} \cdot \frac{d x}{d t}}
$$

By combining the relations (17) and (18), we get:

$$
\frac{d y}{d t}+\frac{(p-q)}{p} \cdot \alpha y=-\frac{(p-q)}{p} \beta
$$

Relation (19) can be written as:

$$
\frac{d y}{d t}+P(t) \cdot y=Q(t)
$$

The solution of this equation is [21]:

$$
y(t)=e^{-\int_{0}^{t} P(t) d t} \cdot\left(\int_{0}^{t} Q(t) \cdot e^{-\int_{0}^{t} P(t) d t} d t+C_{0}\right)
$$

Where: $C_{0}=y(0)$. From relations (19), (20) and (21). We get the expression of $\mathrm{y}(\mathrm{t})$ as :

$$
y(t)=-\frac{\beta}{\alpha}+\frac{\beta}{\alpha} \cdot e^{-\frac{(p-q)}{p} \alpha t}+y(0) \cdot e^{-\frac{(p-q)}{p} \alpha t}
$$

we assume that for $\mathrm{t}=\mathrm{t}_{\mathrm{s}}: \mathrm{x}\left(\mathrm{t}_{\mathrm{s}}\right)=0$ and $\mathrm{y}(\mathrm{ts})=0$.

$$
e^{\frac{p-q}{p} \cdot \alpha t_{S}}=\frac{\beta+\alpha \cdot y(0)}{\beta}
$$

From the initial state $x(0) \neq 0$ for $\mathrm{t}=0$, the convergence time $\mathrm{t}_{\mathrm{S}}$ is then expressed by [22]:

$$
t_{S}=\frac{p}{\alpha(p-q)} \cdot \ln \left(\frac{\alpha \cdot x(0)^{\frac{p-q}{p}}+\beta}{\beta}\right)
$$

\subsubsection{Controller Synthesis}

According to Figure 1, the global references of the rotor currents $\left(i r_{q}^{* *}, i r_{d}^{* *}\right)$ consist of the references of the MPPT block and of the harmonic reference generator. Initially, we define the following errors [23], [24]:

$$
\left\{\begin{array}{l}
e_{1}=i r_{q}-i r_{q}^{* *} \\
e_{2}=i r_{d}-i r_{d}^{* *}
\end{array}\right.
$$

Let us consider the following sliding functions:

$$
\left\{\begin{array}{l}
S_{\mathrm{q}}=\dot{e}_{1}+\alpha_{1} e_{1}+\beta_{1} e_{1}^{q_{1} / p_{1}} \\
S_{\mathrm{d}}=\dot{e}_{2}+\alpha_{2} e_{2}+\beta_{2} e_{2}^{q_{2} / p_{2}}
\end{array}\right.
$$

When $\mathrm{S} 1$ and $\mathrm{S} 2$ converge towards 0 , the errors e1 and e2 also converge towards 0 in finite time.

$$
\left\{\begin{array}{l}
\dot{e}_{1}=-\alpha_{1} e_{1}-\beta_{1} e_{1}^{q_{1} / p_{1}} \\
\dot{e}_{2}=-\alpha_{2} e_{2}-\beta_{2} e_{2}^{q_{2} / p_{2}}
\end{array}\right.
$$

From the relations (25) and (27) we get: 


$$
\left\{\begin{array}{l}
\frac{d i r_{q}}{d t}=\frac{d i r_{q}^{* *}}{d t}-\alpha_{1} e_{1}-\beta_{1} e_{1}^{q_{1}} / p_{1} \\
\frac{d i r_{d}}{d t}=\frac{d i r_{d}^{* *}}{d t}-\alpha_{2} e_{2}-\beta_{2} e_{2}^{q_{2}} / p_{2}
\end{array}\right.
$$

Combining (6) and (28), we establish the following control laws:

$$
\begin{aligned}
& v r_{q}=L_{r} \sigma \frac{d i_{q}^{* *}}{d t}+R_{r} i r_{q}+L_{r} \sigma \omega_{r} i r_{d}+\frac{L_{m} \omega_{r}}{L_{S}} \emptyset_{S}-L_{r} \sigma \alpha_{1} e_{1}-\beta_{1} L_{r} \sigma e_{1}^{q_{1} / p_{1}} \\
& v r_{d}=L_{r} \sigma \frac{d i_{d}^{* *}}{d t}+R_{r} i r_{d}-L_{r} \sigma \omega_{r} i r_{q}+L_{r} \sigma \alpha_{2} e_{2}-\beta_{2} L_{r} \sigma e_{2}^{q_{2} / p_{2}}
\end{aligned}
$$

\section{SIMULATION RESULTS AND ANALYSIS}

In this section, we use the previous equations to simulate both the generator, non-linear load and the controller. In [25], we had already dealt MPPT system. Thus, in this simulation, we focus on the performances of the FTSMC technique control and the mitigation of harmonic currents generated by a nonlinear load. Then, a comparison of its performance to that of the second order sliding mode adopted previously is presented in [10]. System performances have been validated by simulation in MATLAB/SIMULINK environment. The Tables 1 and 2 summarize the parameters of the turbine and DFIG [26]. While Table 3 contain the controller's parameters. The DC link voltage is initially set at 800V.

Figures 4(a) and 4(b) show the shape of the non-linear load currents and its harmonic analysis. The non-linear load introduces harmonic currents with a high THD $(\mathrm{THD}=31.35 \%)$. To get satisfactory results from the proposed method, the currents of the non-linear load must not exceed $10 \%$ of the nominal stator currents generated by the DFIG.

Table 1. The parameters of turbine

\begin{tabular}{llll}
\hline Parameters & Values & Parameters & Values \\
\hline $\mathrm{P}_{\mathrm{N}}$ & $1.5 \mathrm{MW}$ & $\rho$ & $1.225 \mathrm{Kg} / \mathrm{m}^{3}$ \\
Nombre of Blades & 3 & Blade length & $35.25 \mathrm{~m}$ \\
\hline
\end{tabular}

Table 2. The parameters of DFIG

\begin{tabular}{clcl}
\hline Parameters & Values & Parameters & Values \\
\hline $\mathrm{P}_{\mathrm{N}}$ & $1.5 \mathrm{MW}$ & $\mathrm{L}_{\mathrm{r}}$ & $0.0136 \mathrm{H}$ \\
$\mathrm{R}_{\mathrm{S}}$ & $0.012 \Omega$ & $\mathrm{L}_{\mathrm{M}}$ & $0.0135 \mathrm{H}$ \\
$\mathrm{R}_{\mathrm{r}}$ & $0.021 \Omega$ & $\mathrm{F}$ & $0.0024 \mathrm{~N} / \mathrm{rd} / \mathrm{s}$ \\
$\mathrm{Ls}$ & $0.0137 \mathrm{H}$ & $\mathrm{J}$ & $0.175 \mathrm{~kg} . \mathrm{m}$ \\
\hline
\end{tabular}

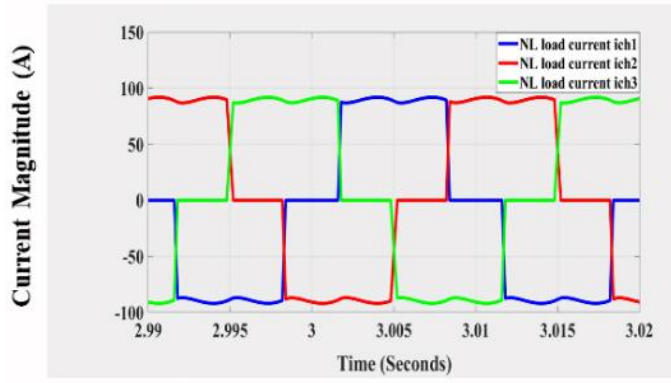

(a)
Table 3. Controller parameters by FTSMC

\begin{tabular}{cccc}
\hline Parameters & Values & Parameters & Values \\
\hline $\mathrm{q}_{1}$ & 10 & $\mathrm{q}_{2}$ & 10 \\
$\mathrm{p}_{1}$ & 11 & $\mathrm{p}_{2}$ & 11 \\
$\alpha_{1}$ & 15 & $\alpha_{2}$ & 5 \\
$\beta_{1}$ & 500 & $\beta_{2}$ & 100 \\
\hline
\end{tabular}

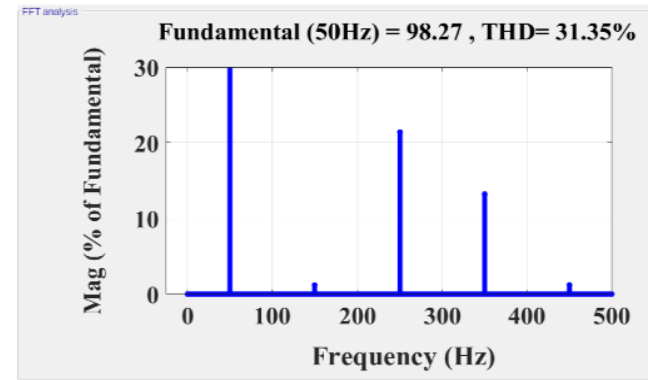

(b)

Figure 4. Shape of non-linear load currents and it FFT analysis; (a) non-linear load currents and (b) FFT analysis

In Figure 5, it's shown the evolution of the wind speed at the system input. In fact, at $\mathrm{t}=3 \mathrm{~s}$ a positive step of $4.5 \mathrm{~m} / \mathrm{s}$ is added to the wind speed. This allows to produce more wind power and generate higher currents on the power system. Figures 6 (a) and 6 (b) show the shape of the electrical network currents generated after compensation of the harmonic currents based on the technique of second order sliding modes. While Figures 6 (c) and 6 (d) show the shapes of the currents when the FTSMC method has been adopted. 
One can note a fast convergence for the FTSMC technique compared to the method applying the sliding mode of the second order. On the other hand, the FFT analysis of the network currents shows a better harmonic rate for the second order sliding mode $0.76 \%$; while the FTSMC technique provides a rate of $1.77 \%$.

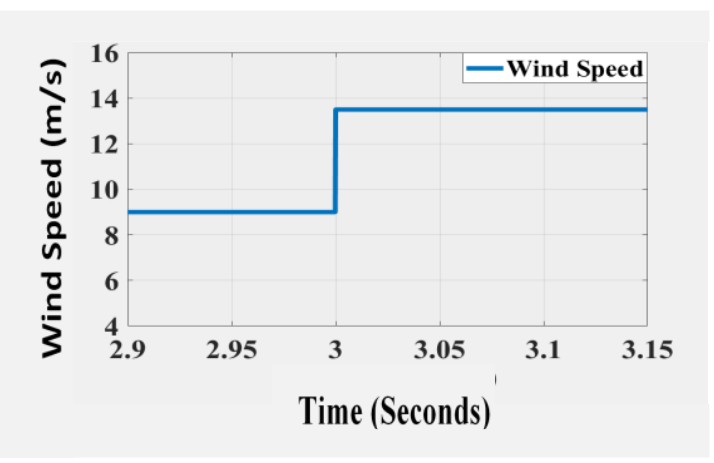

Figure 5. Change of the wind velocity in $(\mathrm{m} / \mathrm{s})$

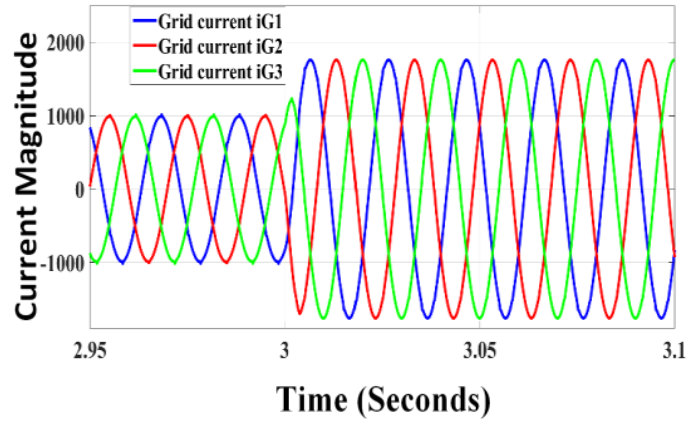

(a)

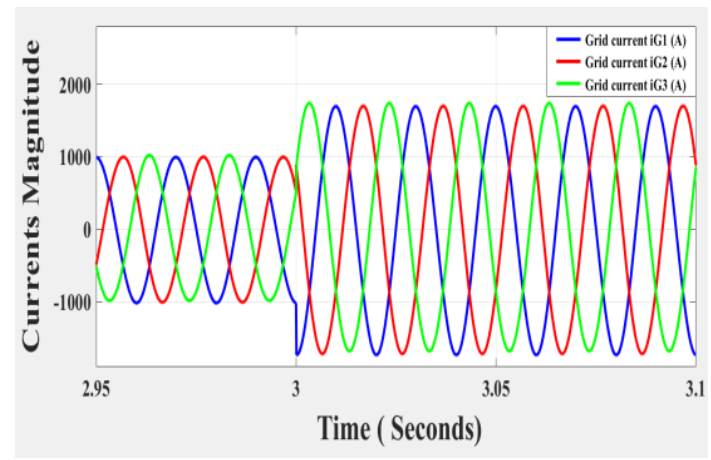

(c)

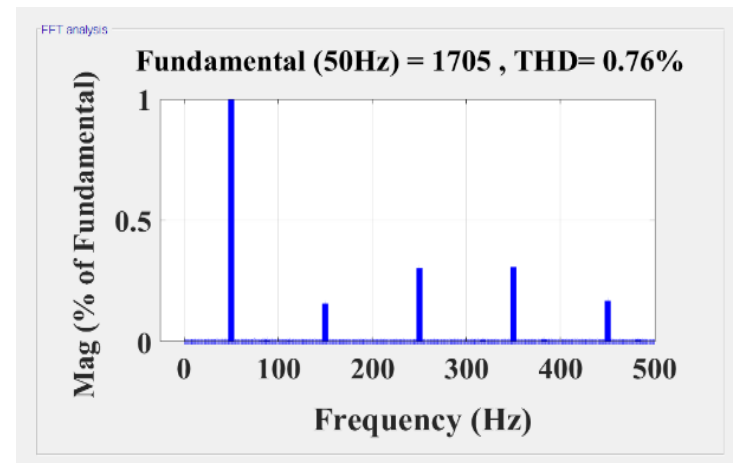

(b)

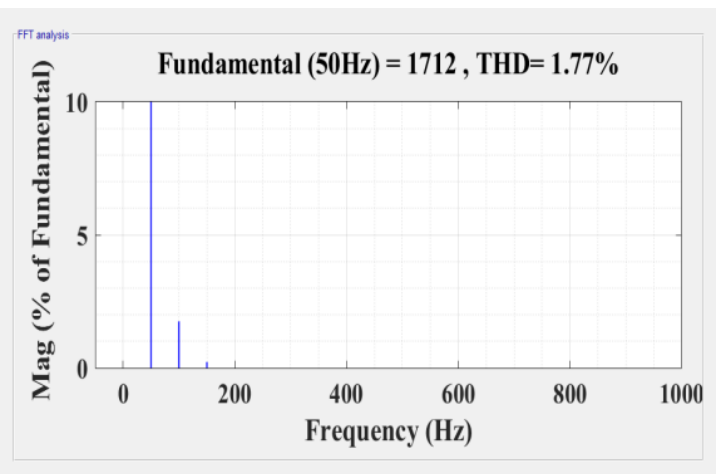

(d)

Figure 6. Shape of the power network currents after compensation; (a) grid current with second order SMC; (b) FFT analysis currents with second order SMC; (c) grid current with FTSMC controller; (d) FTT analysis currents with FTSMC controller

Figure 7 (a) and 7 (b) show the shape and spectral analysis of the currents generated at the stator of the doubly fed induction generator DFIG. It has a better harmonic distortion rate THD estimated at $0.71 \%$. Also, Figure 7 (c) shows a rapid convergence of the currents in the stator of the generator when the FTSMC technique is adopted. Figure 8 shows for the FTSMC technique, the shape of the simple voltage and the line current of the power system. Moreover, the system presents a unit power factor. 


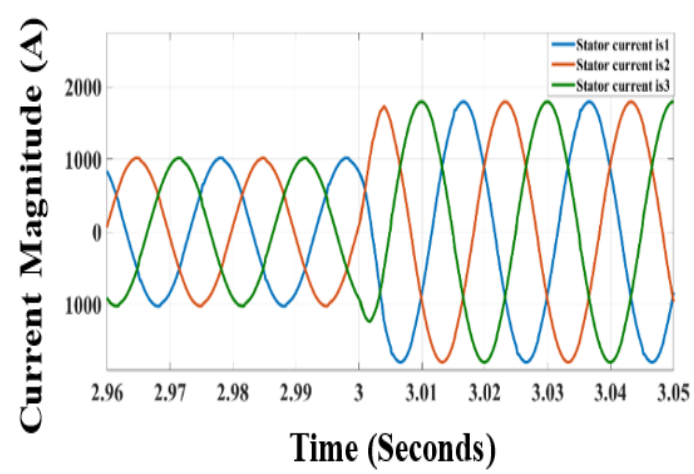

(a)

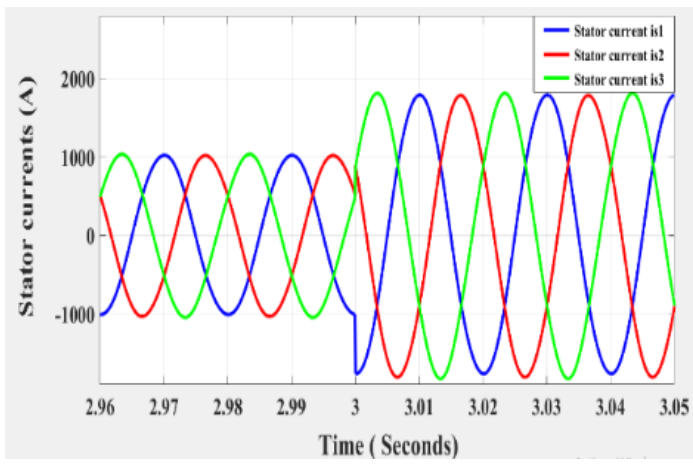

(c)

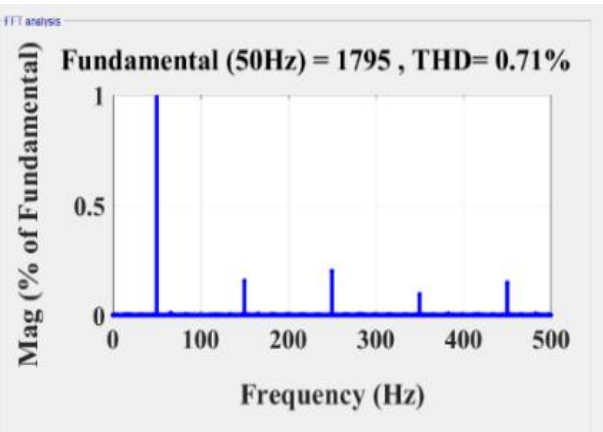

(b)

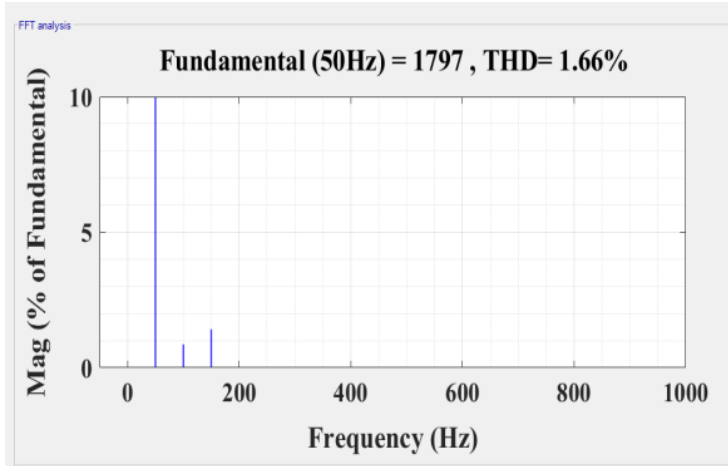

(d)

Figure 7. Shape of the stator currents of the DFIG; (a) stator currents with second order SMC; (b) FFT analysis of stator current with second order SMC; (c) Stator current with FTSMC controller; (d) FFT analysis of stator current with FTSMC

Figure 9 shows the shape of the rotor currents when the wind speed changes from $9 \mathrm{~m} / \mathrm{s}$ to $13.5 \mathrm{~m} / \mathrm{s}$. It show small oscillations caused by the non-linear load. Figure 10 shows the shape of three-phase rotor voltages. These are the DFIG control voltages generated by "RSC" the DC/AC converter. There is a minimum of chatter phenomenon compared to a control by conventional sliding mode. Moreover, it leads to reduce oscillations caused by the high frequency switching of a sliding mode controller. Finally, Figure 11 presents quadratic components of the sliding functions $\mathrm{Sq}$ and $\mathrm{Sd}$. They are characterized by fast convergences towards 0 . This proves the robustness of the control law using high-order sliding mode.

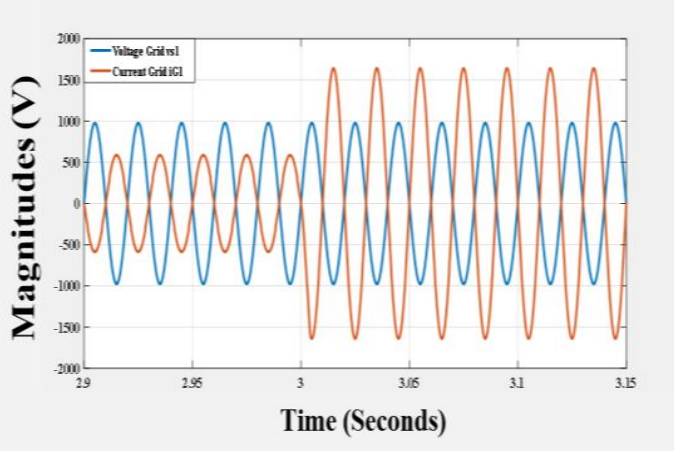

Figure 8. Voltage and current of one phase of grid

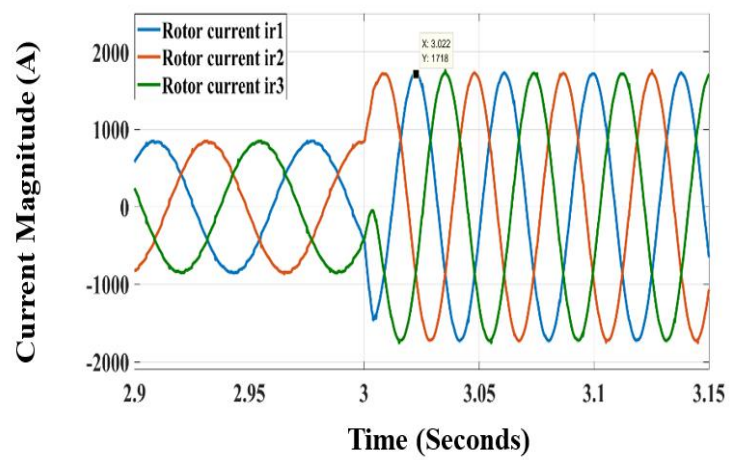

Figure 9. Shape of the rotor currents of DFIG 


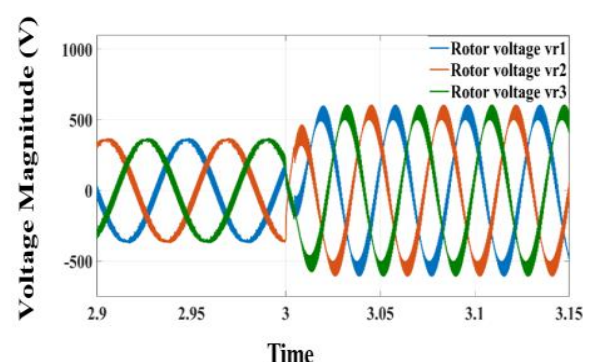

Figure 10. Shape of the rotor voltages of DFIG

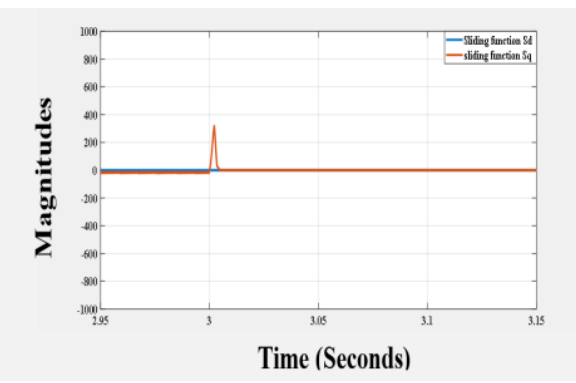

Figure 11. Shape of the sliding function $\mathrm{Sq}$ and $\mathrm{Sd}$

\section{CONCLUSION}

In this paper, an advanced shunt active filtering function of current harmonics generated by nonlinear load on the power system. The strategy used the control of a wind energy conversion system, both to produce active power to the electrical network and to mitigate the current harmonic effects. The studied system is composed of Turbine 1.5 MW three- blades and a doubly fed induction generator DFIG 1.5 MW with the stator directly connected to the grid and the rotor connected to the grid through two converters "RSC" and "GSC". The main objective is the development of an active filtering function performed by the same control of the rotor side converter RSC. While the previous control was used only to allow the wind generator to track optimum operating points under fluctuating wind conditions and to produce high-quality stator energy. The technique of harmonic attenuation use precise identification of the harmonic currents and compensation based on the widely used, instantaneous active and reactive powers theory "PQ" which has given very good results, despite the difficult adjustment of the regulator parameters based on second order sliding mode.

The FTSMC technique adopted in this work, offers a rapid convergence of the currents and a higher harmonic distortion rate compared to the value found by the second order sliding mode control. Despite a little presence of chattering phenomenon compared to a classic sliding mode control for sure due to hidden dynamics of the system. With a view to improving the control law proposed in our work, it is possible to reduce the chattering phenomenon effectively when the fuzzy sliding mode control based on an equivalent control is adopted. The strategy adopted is an attractive option for the network manager because its implementation provides an economic investment for the system. Indeed, the system requires only installation of two or three current sensors at the source station. Moreover, the strategy developed and presented in this work meets with the objectives. This contributes to increasing the reliability of the WECS and improves the quality and efficiency of energy provided to the electrical network.

\section{REFERENCES}

[1] H. S. Naji and H. I. Hussein, "Application of computational methods for harmonic state estimation of power system networks," Indonesian Journal of Electrical Engineering and Computer Science (IJEECS), vol. 22, no.1, pp. 1-9, 2021, doi: 10.11591/ijeecs.v22.i1.pp1-9.

[2] J. Faiz, M. Ghazizadeh, and H. Oraee, "Derating of transformers under non-linear load current and non-sinusoidal voltage - an overview," IET Electric Power Applications, vol. 9, no. 7, pp. 486-495, 2015, doi:10.1049/ietepa.2014.0377.

[3] N. Usha, P. Prasad, and K. Reddy, "Analysis of Effects of Input Current Sub Harmonics and Inter Harmonics on Induction Motor Drive," International Review of Automatic Control (IREACO), vol. 11, no. 1, pp. 23-28, 2018, doi: 10.15866/ireaco.v11i1.13531.

[4] M. Taleb and M. Cherkaoui, "Optimal Control of Active and Reactive Powers in Wind Energy Conversion Systems Using Particle Swarm Optimization and Adaptive Sliding Mode Control," International Review of Automatic Control (IREACO), vol. 11,no. 5, pp. 248-254, 2018, doi:10.15866/ireaco.v11i5.15098.

[5] N. A. Prashanth and P. Sujatha, "Commonly used Wind Generator Systems: A Comparison Note," Indonesian Journal of Electrical Engineering and Computer Science (IJEECS), vol. 7, no.2, pp. 299-311, 2017, doi: 10.11591/ijeecs.v7.i2.pp299-311.

[6] Y. Ihedrane, C. El Bekkali, M. El Ghamrasni, S. Mensou, and B. Bossoufi, "Improved wind system using nonlinear power control," Indonesian Journal of Electrical Engineering and Computer Science (IJEECS), vol. 14, no.3, pp. 1148-1158, 2019, doi: 10.11591/ijeecs.v14.i3.pp1148-1158.

[7] A. Andang, R. Hartarti, I. Manuaba, and I. Kumara, "Harmonics Reduction on Electric Power Grid Using Shunt Hybrid Active Power Filter with Finite-Control-Set Model-Predictive Control," International Review on Modelling and Simulations (IREMOS), vol. 13, no. 1, pp. 52-62, 2020, doi: 10.15866/iremos.v13i1.17891.

[8] Y. Hoon, M. Mohd Radzi, M. Hassan, and N. Mailah, "Control Algorithms of Shunt Active Power Filter for Harmonics Mitigation: A Review,” Energies, vol. 10, no. 12, p. 2038, Dec. 2017, doi:10.3390/en10122038. 
[9] Y. Kanazawa, H. Akagi, and A. Nabae, "Generalized theory of the instantaneous reactive power in three-phase circuits," Proceeding International, power electronics conference, Tokyo, Japan, vol. 103, no. 4, pp. 1375-1386, 1983, doi: 10.1002/eej.4391030409.

[10] A. Touati, R. Majdoul, M. L. Pierre, and N. Rabbah, "Harmonic mitigation using shunt active filtering function based a Wind Energy Conversion System equipped with double fed induction generator DFIG," In 2020 International Conference on Electrical and Information Technologies (ICEIT), Rabat, Morocco, 2020, pp. 1-6, doi: 10.1109/ICEIT48248.2020.9113196.

[11] H. Akagi, A. Nabae, and S. Atoh. "Control strategy of active power filters using multiple voltage-source pwm converters,” In IEEE Trans. Ind. Appl., vol. vol. IA-22, no. 3, pp. 460-465, 1986, doi: 10.1109/TIA.1986.4504743.

[12] G. E. Ahmed and H. H. Ali, "Grid Side Converter Based Shunt Active Power Filter of Variable Speed Doubly Fed Induction Generator Driven by Wind Turbine," Int. Journal of Science and Research (IJSR), vol. 6, no. 9, 2017.

[13] A. R. Lopez, G. Vazquez, J. M. Sosa, M. A. Juarez, and C. Correa-Betanzo, "Current Harmonics Mitigation in a Wind Energy Conversion System Through the Selection of the PI Control Parameters in the Rotor Side Converter," In 14th International Conference on Power Electronics (CIEP), Cholula, 2018, pp. 168-173, doi: 10.1109/CIEP.2018.8573396.

[14] A. Touati, A. Abouloifa, E. Abd Elmounim, M. Aboulfatah, R. Majdoul, and A. Moutabir, "Design of an Mppt based on the Torque Estimator for Variable Speed Turbines," International Conference on Electrical and Information Technologies (ICEIT), 2015, pp. 166-171, doi: 10.1109/EITech.2015.7162964.

[15] J. Xiong and G. Zhang, "Global fast dynamic terminal sliding mode control for a quadrotor UAV", ISA Transactions, vol. 66, 2017, pp. 233-240, doi: 10.1016/j.isatra.2016.09.019.

[16] E. Aydin, A. Polat, and L. T. Ergene, "Vector control of DFIG in wind power applications," 2016 IEEE International Conference on Renewable Energy Research and Applications (ICRERA), Birmingham, 2016, pp. 478-483, doi: 10.1109/ICRERA.2016.7884383.

[17] B. Beltran, M. Benbouzid, T. Ahmed-Ali, and H. Mangel," DFIG-Based Wind Turbine Robust Control Using High-Order Sliding Modes and a High Gain Observer," International Review on Modelling and Simulations (I. RE.MO.S.), vol. 4, no. 3, p. 1148, June 2011.

[18] M. A. Kamarposhti, "Power Quality Compensation in Distribution System based on Instantaneous Power Theory and Recursive Fuzzy Proportional-Integral Controller," International Journal of Electrical and Computer Engineering (IJECE), vol. 8, no. 1, pp 538-543, 2018 doi: 10.11591/ijece.v8i1.pp538-543.

[19] C. M. Thuyen, "Improved p-q Harmonic Detection Method for Hybrid Active Power Filter," International Journal of Electrical and Computer Engineering (IJECE). vol. 8, no. 5, pp. 2910-2919, 2018, doi: 10.11591/ijece.v8i5.pp2910-2919.

[20] E. Heydari, A. Y. Varjani and D. Diallo, "Fast terminal sliding mode control-based direct power control for single-stage single-phase PV system," Control Engineering Practice, vol. 104, 2020, doi: 10.1016/j.conengprac.2020.104635.

[21] M. S. Marathe and S. M. Srinivasan, "Dynamic fast terminal sliding mode control of a shape memory alloy actuated system," Active and Passive Smart Structures and Integrated Systems 2016, vol. 9799, Apr. 2016, doi: $10.1117 / 12.2229885$.

[22] J. Sun, S. Song, H. Chen, and G. Wu," Fast terminal sliding mode tracking control of hypersonic vehicles based on non-homogeneous disturbance observer," International Journal of Control, Automation, and Systems, vol. 15, no. 6, pp. 2646-2659, 2017, doi: 10.1007/s12555-016-0785-0.

[23] F. Mehedi, R. Taleb, A. B. Djilali, and A. Yahdou, "SMC based DTC-SVM control of five-phase permanent magnet synchronous motor drive," Indonesian Journal of Electrical Engineering and Computer Science (IJEECS), vol. 20, no.1, pp. 100-108, 2020, doi: 10.11591/ijeecs.v20.i1.pp100-108.

[24] Y. C. Koo and M. N. Mahyuddin, "An enhanced distributed control-theoretic time synchronization protocol using sliding mode control for wireless sensor and actuator network," Indonesian Journal of Electrical Engineering and Computer Science (IJEECS), vol. 14, no. 2, pp. 688-696, 2019, doi: 10.11591/ijeecs.v14.i2.pp688-696.

[25] A. Touati, E. Abdelmounim, M. Aboulfatah, A. Moutabir, and R. Majdoul "Improved Strategy of an MPPT Based on the Torque Estimator for Variable Speed Turbines," International Review on Modelling and Simulations (I.RE.MO.S.), vol. 8, no. 6, ISSN 1974-9821, Dec. 2015, doi: 10.15866/iremos.v8i6.7122.

[26] S. Abdeddaim and A. Betka, "Optimal tracking and robust power control of the DFIG wind turbine," International Journal of Electrical Power \& Energy Systems, vol. 49, pp. 234-242, 2013, doi: 10.1016/j.ijepes.2012.12.014.

\section{BIOGRAPHIES OF AUTHORS}

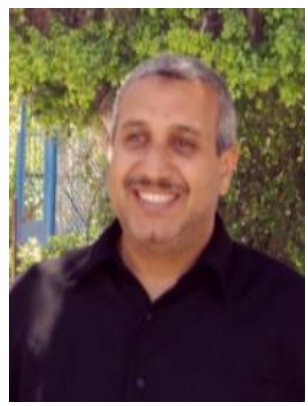

Abdelwahed Touati was born in Casablanca, Morocco, in 1970. In 1999, he successfully passed the external aggregation contest. He received her $\mathrm{PhD}$ degree in Automatic Signal Processing and Industrial Computing Automation and Industrial in 2017 from Hassan I University- FST of Settat Morocco. Currently he is Research Professor Laboratory of Structural Engineering, Intelligent Systems \& Electrical Energy ENSAM, and Department of Electrical Engineering-Hassan II University Casablanca, Morocco. His research interests include control strategies for AC machine Drives, renewable energy and Power Quality. 


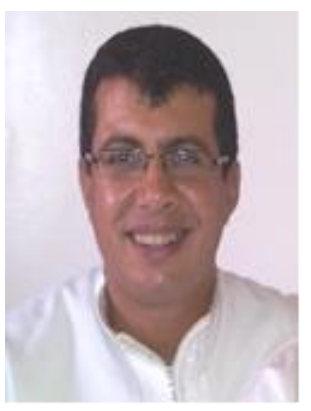

Radouane Majdoul was born in Meknes, Morocco, in 1969. In 1997, he successfully passed the external aggregation contest. He received her PhD degree in Automatic Signal Processing and Industrial Computing Automation and Industrial in 2017 from Hassan I University-FST of Settat Morocco. Currently he is Research Professor Laboratory of Structural Engineering, Intelligent Systems \& Electrical Energy ENSAM, hassan II University, Morocco.

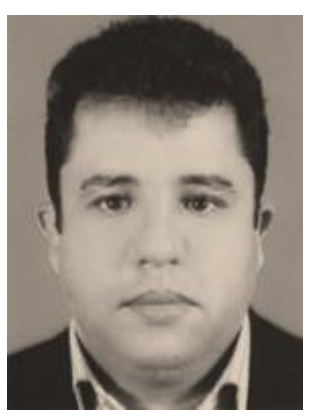

Mohamed Aboulfatah was born in Casablanca Morocco in 1967; he received his $\mathrm{PhD}$ in Measures and Instrumentation from Bordeaux university, France in 1994. From 1993 to 1995, he was associated professor at the Technological Institute of Bordeaux University. In 1996, he joined, as permanent Professor, applied physics department of science and technical faculty, Hassan $1^{\text {st }}$ University, Settat, Morocco.

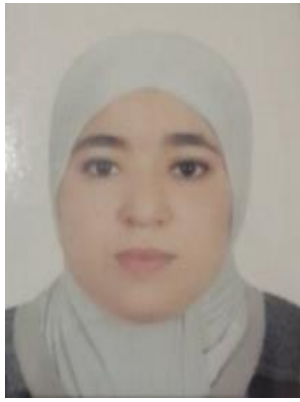

Nabila Rabbah is a state electric engineer from the ENSEM of Casablanca. She obtained her master degree in Industrial Automation from ENSEM-Casablanca, and then she received her $\mathrm{PhD}$ degree in Automation and Industrial IT in 2008 from Hassan II University of Casablanca, Morocco. Since 2011, she is a professor in the department of electric engineering of the ENSAM-Casablanca. She is a coordinator of the research team "Modeling, Control and Embedded Systems". She contributes by numerous publications in the field of the command. 